\title{
Result Analysis of Power Quality Improvement Features for Grid-Connected Space Vector Pulse Width Modulation Features
}

\author{
Nilesh Prajapat ${ }^{1}$, Ashish Bhargava ${ }^{2}$, Priyanka Mishra ${ }^{3}$ \\ M.Tech Scholar, Bhabha Engineering Research Institute Bhopal, India ${ }^{1}$ \\ Associate Prof, Bhabha Engineering Research Institute Bhopal, India ${ }^{2,3}$
}

\begin{abstract}
This paper presents Space Vector Pulse Width Modulation scheme to enhance the power quality and responsibility of the microgrid system. The planned scheme is comprised of two inverters that allow the microgrid to exchange power generated by the distributed energy resources (DERs) and in addition to compensate the local unbalanced and nonlinear load. The planned scheme has increased responsibleness, lower bandwidth demand of the most inverter, lower cost as a result of reduction in filter size, and better utilization of microgrid power whereas using reduced dc-link voltage rating for the most inverter. These choices build the SVSI scheme a promising option for small grid provision sensitive hundreds.
\end{abstract}

Keywords: Grid-connected inverter, instantaneous symmetrical component theory (ISCT), microgrid, power quality.

\section{INTRODUCTION}

Flexible operation of distributed generation (DG) units could also be a significant objective in future wise power grid [1]-[4]. The majority of dg units are interfaced to grid/load via power electronics converters. Current-controlled voltage-sourced inverters (VSIs) are typically used for grid connection [5]. Under the sensible grid atmosphere, dg units need to be enclosed inside the system operational management framework, wherever they're going to be accustomed enhance system responsibility by providing backup generation in isolated mode, and to provide auxiliary services (e.g. voltage support and reactive power control) within the grid-connected mode. These operational management actions are dynamic in nature as they depend on the load/generation profile, demand-side management control, and overall network improvement controllers (e.g., grid reconfiguration and superior management actions) [4]. to realize this vision, the dg interface need to give high flexibility and robustness in meeting a good vary of management functions, like seamless transfer between grid-connected operation and islanded mode; seamless transfer between active/reactive power (PQ) and active power/voltage (PV) modes of operation within the grid connected mode; robustness against islanding detection delays; providing minimal control-function switch throughout mode transition; and maintaining a hierarchical control structure. Technological progress and environmental problems drive the ability system to a paradigm shift with further renewable energy sources integrated to the network by means that of distributed generation (DG). These weight units with coordinated management of native generation and storage facilities type a microgrid [1].

During a microgrid, power from different renewable energy sources like fuel cells, electrical phenomenon (PV) systems, and wind energy systems are interfaced to grid and loads using power electronic converters. A grid interactive inverter plays a very important role in exchanging power from the microgrid to the grid and additionally the connected load [2], [3]. This microgrid inverter will either add a grid sharing mode whereas supplying partity of local load or in grid injecting mode, by injecting power to the main grid.

Three phase voltage-fed PWM inverters are newly showing rising quality for multi-megawatt manufacturing drive applications. The main reasons for this quality are easy sharing of huge voltage between the series devices and also the improvement of the harmonic quality at the output as compared to a 2 level inverter. Within the lower end of power, GTO devices are being replaced by IGBTs due to their fast evolution in voltage and current ratings and better switching frequency. The space Vector Pulse width Modulation of a 3 level inverter provides the additional advantage of superior harmonic quality and larger under-modulation vary that extends the modulation issue to $90.7 \%$ from the normal value of $78.5 \%$ in sinusoidal Pulse width Modulation.

This work demonstrates a dual voltage source inverter (DVSI) scheme, within which the power generated by the microgrid is injected as real power by the most voltage supply converter (MVSI) and additionally the hasty, harmonic, 
and disturbed load compensation is performed by auxiliary voltage source inverter (AVSI). This has an advantage that the rated capability of MVSI will always be used to inject real power to the grid, if sufficient renewable power is offered at the dc link. Within the DVSI scheme, as total load power is provided by 2 inverters, power losses across the semiconductor switches of every inverter are reduced. This will increase its dependability as compared to one inverter with multifunctional capabilities.

\section{THEORY}

The utilization of wind energy is an area that is growing rapidly. In Europe, the put in wind power has increased by 36 which each year for five years, now. In northern Germany, wind turbine manufacture is that the fastest growing trade. Moreover, wind energy covers seven make the most Danish electricity consumption. Most countries in Europe have plans for increasing their share of energy created by wind power. The increased share of wind power within the electrical power system makes it necessary to have grid-friendly interfaces between the wind turbines and therefore the grid so as to maintain power quality.

In addition, power physics is undergoing a fast evolution, principally because of 2 factors. The primary issue is that the development of fast semiconductor valves, that are capable of switching fast and handling high powers. The second issue is that the control area, wherever the introduction of the pc as a time period controller has created it possible to adapt advanced and complex control algorithms. These factor along build it possible to have cost-efficient and gridfriendly converters connected to the grid.

Maintain power quality is a different important aspect which has to be address while the micro grid system is linked to the main grid. The proliferation of power electronics devices and electrical loads with unbalanced nonlinear currents has degraded the power quality in the power distribution net- work. Moreover, if there is a considerable amount of feeder impedance in the distribution systems, the propagation of these harmonic currents distorts the voltage at the point of common coupling (PCC). At the same instant, industry automation has reached to a very high level of sophistication, where plants like automobile manufacturing units, chemical factories, and semiconductor industries require clean power. For these applications, it is essential to compensate nonlinear and unbalanced load currents. Load compensation and power injection using grid interactive inverters in micro grid have been presented in the literature. A single inverter system with power quality enhancement is discussed in. The main focus of this work is to realize dual functionalities in an inverter that would give the active power injection from a solar PV system and also works as an active power filter, compensating unbalances and the reactive power required by other loads connected to the system..

\section{III.METHOD}

The planned methodology describes Space vector modulation (SVM) is one of the ideal real-time modulation technique and is generally used for digital control of voltage source inverters. The operating status of the switches in the two-level inverter in Fig. 5.1 can be represented by switching states. As indicated in Table 1, switching state ' $\mathrm{P}$ ' denote that the higher switch in an inverter support is on and the inverter terminal voltage (VAN, VBN, or VCN) is positive $(+\mathrm{Vd})$ while ' $\mathrm{O}$ ' indicates that the inverter terminal voltage is zero due to the conduction of the lower switch..

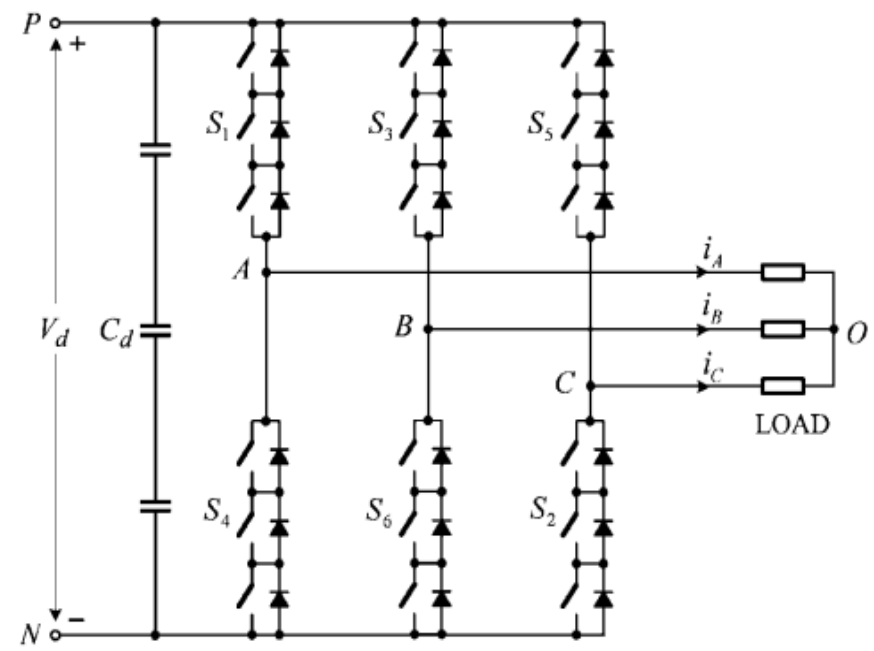

Fig.1 Simplified two-level inverter for high-power applications 


\begin{tabular}{|c|c|c|c|c|c|c|c|c|c|}
\hline \multirow{2}{*}{$\begin{array}{l}\text { Switching } \\
\text { State }\end{array}$} & \multicolumn{3}{|c|}{$\operatorname{Leg} A$} & \multicolumn{3}{|c|}{$\operatorname{Leg} B$} & \multicolumn{3}{|c|}{$\operatorname{Leg} C$} \\
\hline & $S_{1}$ & $S_{4}$ & $v_{A N}$ & $S_{3}$ & $S_{6}$ & $v_{B N}$ & $S_{5}$ & $S_{2}$ & $v_{C N}$ \\
\hline $\mathrm{P}$ & On & Off & $V_{d}$ & On & Off & $V_{d}$ & On & Off & $V_{d}$ \\
\hline 0 & Off & On & 0 & Off & On & 0 & Off & On & 0 \\
\hline
\end{tabular}

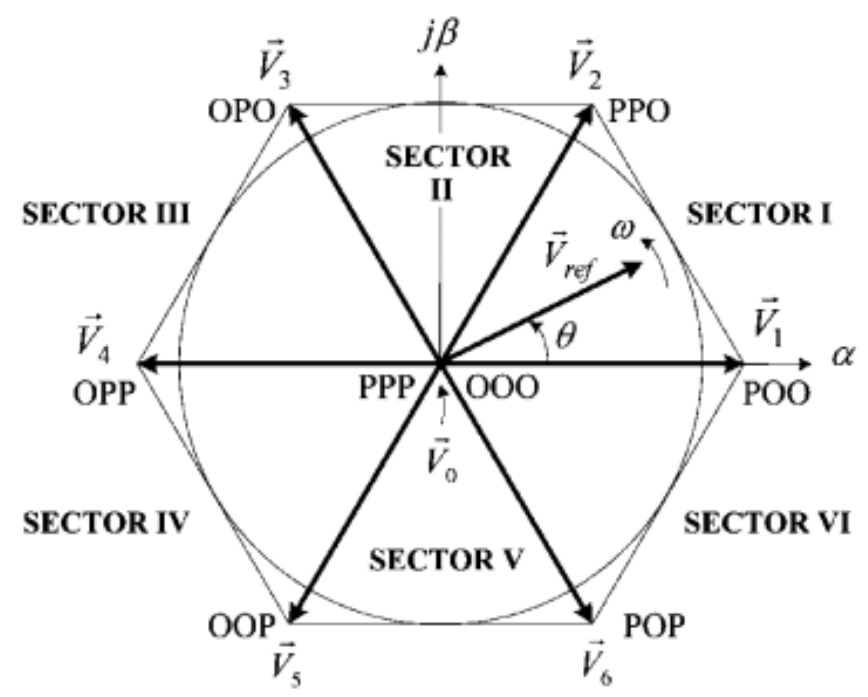

Fig.2 Space vector diagram for the two-level inverter

\section{A. Power Quality}

The contemporary container crane business, like several different industry segments, is usually enamored by the bells and whistles, colourful diagnostic displays, high speed performance, and levels of automation that may be achieved. Though these features and their indirectly connected computer based enhancements are key problems to an efficient terminal operation, we tend to should not forget the foundation upon that we tend to are building. Power quality is that the mortar that bonds the foundation blocks. Power quality additionally affects terminal operational economic science, crane responsibleness, our surroundings, and initial investment in power distribution systems to support new crane installations.

To quote the utility company newsletter that accompanied the last monthly issue of my home utility billing: „Using electricity wisely may be a sensible environmental and business follow that saves you cash, reduces emissions from generating plants, and conserves our natural resources." As we tend to are all aware, container crane performance needs still increase at an astounding rate.

Next generation container cranes, already within the bidding method, will require average power demands of 1500 to 2000 kilowatt - nearly double the full average demand 3 years past. The speedy increase in power demand levels, a rise in container crane population, SCR convertor crane drive retrofits and also the large AC and DC drives required to power and control these cranes can increase awareness of the power quality issue within the very close to future..

\section{IV.RESULT}

Develop a simulation program for the conventional SVM scheme using the seven-segment switching sequence. For each of the above tasks, draw waveforms (two cycles each) for the inverter line-to-line voltage vAB (V) and inverter output current iA (A).

$$
\text { T.1 (f1 = } 30 \mathrm{~Hz}, \mathrm{ma}=\mathbf{0 . 4})
$$


ISO 3297:2007 Certified

Vol. 4, Issue 6, June 2017

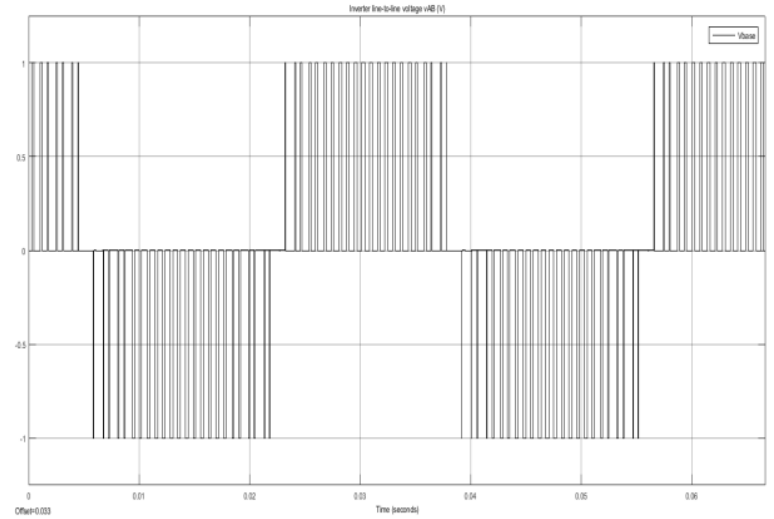

Fig.3 Inverter line-to-line voltage vAB (V)

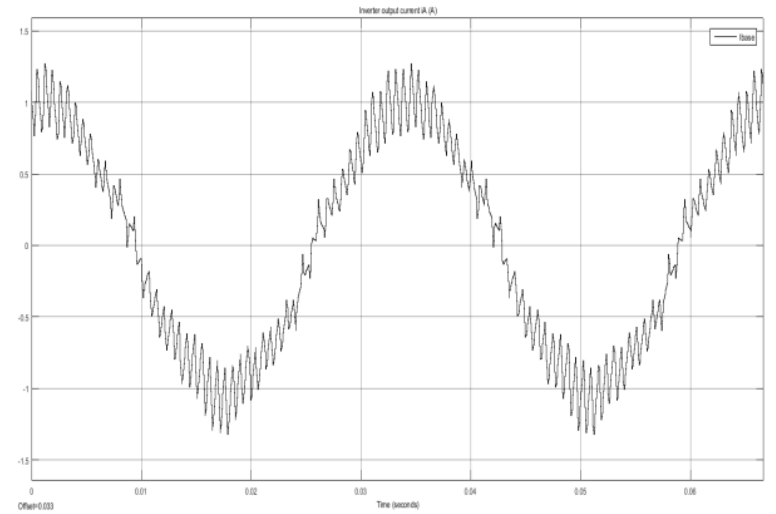

Fig.4 Inverter output current iA (A)
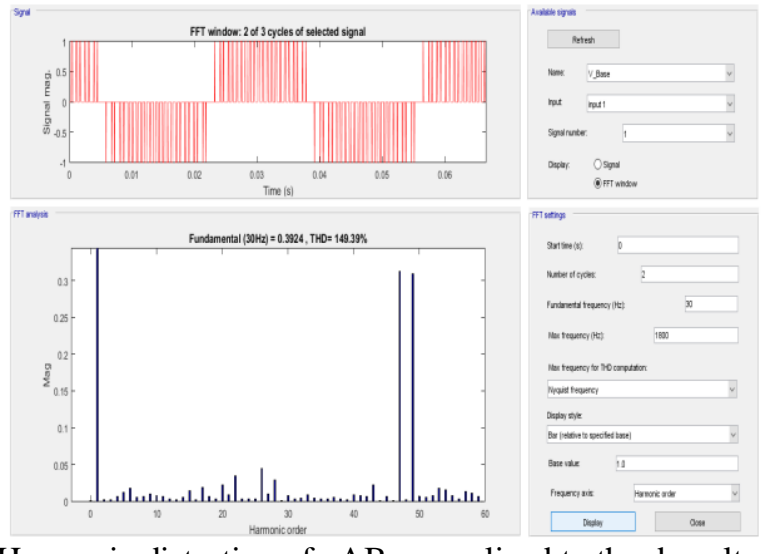

Fig.5Harmonic distortion of $\mathrm{vAB}$ normalized to the dc voltage $\mathrm{Vd}$

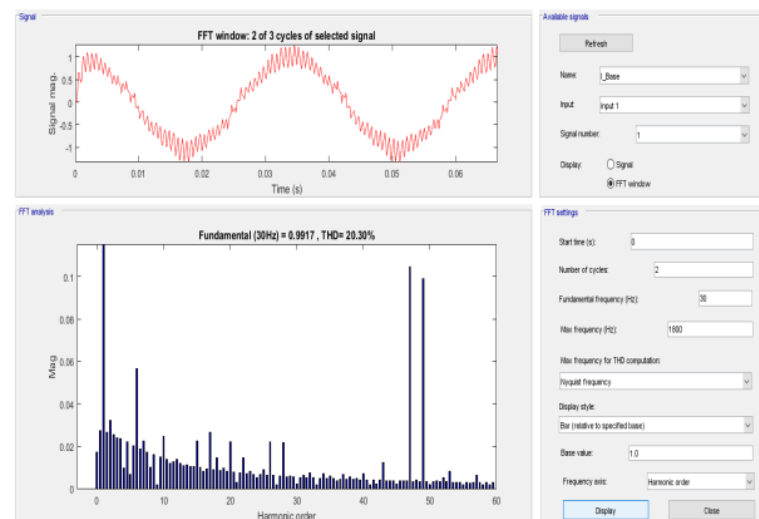

Fig.6 Harmonic distortion of iA normalized to its rated fundamental component IA1,RTD 


\section{IARJSET \\ ISSN (Online) 2393-8021 ISSN (Print) 2394-1588 \\ International Advanced Research Journal in Science, Engineering and Technology ISO 3297:2007 Certified \\ Vol. 4, Issue 6, June 2017}

\section{CONCLUSION}

A SVSI scheme is proposed for microgrid systems with enhanced power quality. Control algorithms are developed to generate reference currents for SVSI using ISCT. The proposed method has the ability to exchange power from distributed generators (DGs) and also to compensate the local unbalanced and nonlinear load. The performance of the proposed scheme has been validated through simulation and experimental studies. Two level inverters are investigated by means of their harmonic distortion. Then in this research work introduce an improved version of space vector modulation by using a modified two level voltage source inverter for eliminating the even-order harmonics. As compared to a single inverter with multifunctional capabilities, a SVSI has many advantages such as, increased reliability, lower cost due to the reduction in filter size, and more utilization of inverter capacity to inject real power from DGs to microgrid. Moreover, the use of 3-phase, 3 wire topology for the main inverter reduce the dc-link voltage requirement. Thus, a SVSI scheme is a suitable interfacing option for microgrid supplying sensitive loads.

\section{REFERENCES}

[1] M. V. Manoj Kumar, Mahesh K. Mishra, and Chandan Kumar “A Grid-Connected Dual Voltage Source Inverter With Power Quality Improvement Features" IEEE Transactions On Sustainable Energy 2015.

[2] Kjaer, Soeren Baekhoej, John K. Pedersen, and Frede Blaabjerg. "A review of single-phase grid-connected inverters for photovoltaic modules" IEEE trans. on industry applications 41.5 (2005): 1292-1306.

[3] Jain, Sachin, and Vivek Agarwal. "A single-stage grid connected inverter topology for solar PV systems with maximum power point tracking" IEEE Transactions on Power Electronics 22.5 (2007): 1928-1940.

[4] Mastromauro, Rosa A., et al. "A single-phase voltage-controlled grid-connected photovoltaic system with power quality conditioner functionality" IEEE Transactions on Industrial Electronics 56.11 (2009): 4436-4444.

[5] Vasquez, Juan C., et al. "Adaptive droop control applied to voltage-source inverters operating in grid-connected and islanded modes" IEEE Transactions on Industrial Electronics 56.10 (2009): 4088-4096.

[6] J. Mukhtiar Singh, Vinod Khadkikar, Ambrish Chandra and Rajiv K. Varma "Grid Interconnection of Renewable Energy Sources at the Distribution Level With Power-Quality Improvement Features” IEEE Transactions On Power Delivery, Vol. 26, No. 1, January 2011.

[7] Ritwik Majumder, Arindam Ghosh, Gerard Ledwich and Firuz Zare "Load Sharing and Power Quality Enhanced Operation of a Distributed Microgrid" I. E. T. Renewable Power Generation 2009.

[8] Alireza Kahrobaeian and Yasser Abdel-Rady I. Mohamed "Interactive Distributed Generation Interface for Flexible Micro-Grid Operation in Smart Distribution Systems" IEEE Transactions on Sustainable Energy, Vol. 3, No. 2, April 2012.

[9] Guerrero, Josep M., et al. “Advanced control architectures for intelligent microgrids-Part II: Power quality, energy storage, and AC/DC microgrids" IEEE Transactions on Industrial Electronics 2013.

[10] H.-G. Yeh, D. Gayme, and S. Low, "Adaptive VAR control for distribution circuits with photovoltaic generators" IEEE Trans. Power Syst., vol. 27, no. 3, pp. 1656-1663, Aug. 2012.

[11] C. Demoulias "A new simple analytical method for calculating the optimum inverter size in grid-connected PV plants" Electr. Power Syst. Res., vol. 80, no. 10, pp. 1197-1204, 2010.

[12] R. Tonkoski, D. Turcotte, and T. H. M. EL-Fouly, "Impact of high PV penetration on voltage profiles in residential neighborhoods" IEEE Trans. Sustain. Energy, vol. 3, pp. 518-527, Jul. 2012.

[13] X. Yu and A. Khambadkone, "Reliability analysis and cost optimization of parallel-inverter system" IEEE Trans. Ind. Electron., vol. 59, no. 10, pp. 3881-3889, Oct. 2012.

[14] M. K. Mishra and K. Karthikeyan, "Design and analysis of voltage source inverter for active compensators to compensate unbalanced and nonlinear loads" in Proc. IEEE Int. Power Eng. Conf., 2007, pp. 649-654.

[15] A. Ghosh and A. Joshi, "A new approach to load balancing and power factor correction in power distribution system" IEEE Trans. Power Del., vol. 15 , no. 1 , pp. 417-422, Jan. 2000.

[16] U. Rao, M. K. Mishra, and A. Ghosh, "Control strategies for load compensation using instantaneous symmetrical component theory under different supply voltages” IEEE Trans. Power Del., vol. 23, no. 4, pp. 2310-2317, Oct. 2008. 